\title{
Machine learning for SMART mineral mapping using coupled XRF-XRD
}

\author{
C.A. PETERS ${ }^{1 *}$, J.J. KIM ${ }^{1}$, F.T. LING ${ }^{1}$, \\ D.A.PlatTENBERGER ${ }^{2}$, A.F. ClARENS ${ }^{2}$
}

${ }^{1}$ Princeton University, Princeton, NJ U.S.A.

(*Correspondence: cap@princeton.edu)

${ }^{2}$ University of Virginia, Charlottesville, VA U.S.A.

A Synchrotron-based Machine learning Approach for RasTer (SMART) mineral mapping was developed to train a mineral classifier that can interpret raster-scanned millimetersized areas of rock thin sections with micron-sized resolution. Training is done using Artificial Neural Networks (ANN) (Figure 1) with coupled micro X-ray fluorescence $(\mu \mathrm{XRF})$ intensities, which provide information about element abundances, and micro X-ray diffraction $(\mu \mathrm{XRD})$ patterns, which provide information about mineral identity.

The resulting SMART mineral mapper can identify minerals using only micro X-ray Fluorescence $(\mu \mathrm{XRF})$ data. The value of this approach comes from the fact that $\mu \mathrm{XRF}$ data are relatively fast to collect and interpret whereas the $\mu$ XRD data take longer to collect and much longer to interpret.

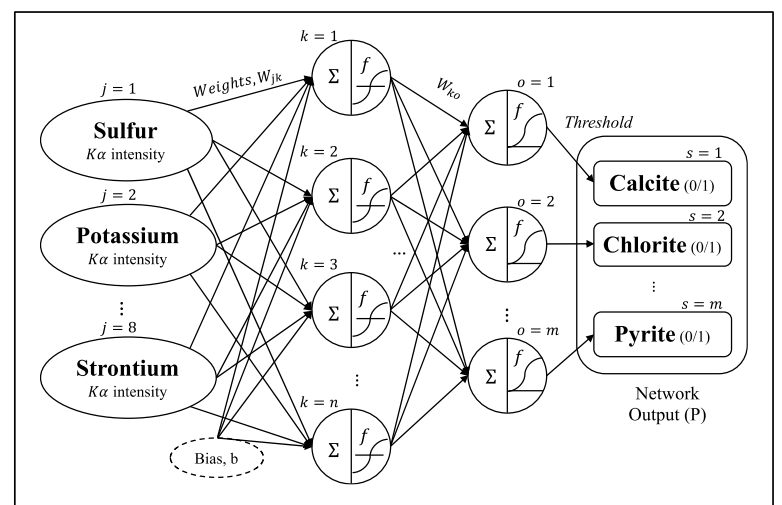

Figure 1. Artificial Neural Network (ANN) for mineral classification from XRF data.

In application to a $14 \mathrm{~mm}^{2}$ area of a thin section of Eagle Ford shale scanned with $2 \mu \mathrm{m}$ resolution, 26 minerals were detected using 8 elements ( $\mathrm{S}, \mathrm{K}, \mathrm{Ca}, \mathrm{Ti}, \mathrm{Mn}, \mathrm{Fe}, \mathrm{As}, \mathrm{Sr}$ ). In the testing phase, all but two of 76 testing data points were correctly classified. 